\title{
Vitamin E succinate-conjugated F68 micelles for mitoxantrone delivery in enhancing anticancer activity
}

This article was published in the following Dove Press journal:

International Journal of Nanomedicine

12 July 2016

Number of times this article has been viewed

\author{
Yuling Liu' ${ }^{1, *}$ \\ Yingqi $\mathrm{Xu}^{2, *}$ \\ Minghui $\mathrm{Wu}^{3}$ \\ Lijiao Fan' \\ Chengwei $\mathrm{He}^{2}$ \\ Jian-Bo Wan ${ }^{2}$ \\ Peng $\mathrm{Li}^{2}$ \\ Meiwan Chen ${ }^{2}$ \\ Hui $\mathrm{Li}^{\prime}$ \\ Institute of Chinese Materia Medica, \\ China Academy of Chinese Medical \\ Sciences, Beijing, People's Republic \\ of China; ${ }^{2}$ State Key Laboratory of \\ Quality Research in Chinese Medicine, \\ Institute of Chinese Medical Sciences, \\ University of Macau, Macau, People's \\ Republic of China; ${ }^{3}$ Department of \\ Cell Biology and Anatomy, School \\ of Medicine, University of Florida, \\ Gainesville, FL, USA
}

*These authors contributed equally to this work

\begin{abstract}
Mitoxantrone (MIT) is a chemotherapeutic agent with promising anticancer efficacy. In this study, Pluronic F68-vitamine E succinate (F68-VES) amphiphilic polymer micelles were developed for delivering MIT and enhancing its anticancer activity. MIT-loaded F68-VES (F68-VES/MIT) micelles were prepared via the solvent evaporation method with self-assembly under aqueous conditions. F68-VES/MIT micelles were found to be of optimal particle size with the narrow size distribution. Transmission electron microscopy images of F68-VES/ MIT micelles showed homogeneous spherical shapes and smooth surfaces. F68-VES micelles had a low critical micelle concentration value of $3.311 \mathrm{mg} / \mathrm{L}$, as well as high encapsulation efficiency and drug loading. Moreover, F68-VES/MIT micelles were stable in the presence of fetal bovine serum for 24 hours and maintained sustained drug release in vitro. Remarkably, the half maximal inhibitory concentration $\left(\mathrm{IC}_{50}\right)$ value of F68-VES/MIT micelles was lower than that of free MIT in both MDA-MB-231 and MCF-7 cells (two human breast cancer cell lines). In addition, compared with free MIT, there was an increased trend of apoptosis and cellular uptake of F68-VES/MIT micelles in MDA-MB-231 cells. Taken together, these results indicated that F68-VES polymer micelles were able to effectively deliver MIT and largely improve its potency in cancer therapy.
\end{abstract}

Keywords: F68, vitamin E succinate, mitoxantrone, polymer micelles, cancer therapy

\section{Introduction}

Mitoxantrone (MIT), an anthracene derivative, is a promising chemotherapeutic agent that has been largely used for the treatment of human malignancies, such as metastatic breast cancer, prostate cancer, acute myeloid leukemia, and non-Hodgkin's lymphoma. ${ }^{1-4}$ MIT has a structure similar to that of anthracyclines, which induces the mitochondrial apoptosis pathway and hinders proliferation by causing DNA damage and disrupting DNA repair or synthesis. ${ }^{2,5}$ In order to enhance the anticancer activity with a low dosage of MIT, we used nanoscale drug carriers to deliver MIT to the cancer cells in this study.

Recently, nanoscale drug carriers with nontoxic, nonimmunogenic, and biodegradable benefits have attracted much attention for delivering chemotherapeutic drugs in cancer treatment since they can enhance the selective distribution via the effect of enhanced permeability and retention (EPR) and reduce inefficient cell uptake and serious side effects compared to traditional anticancer drugs. ${ }^{6-10}$ Polymeric micelles formed by amphiphilic polymers belonging to nanoscale drug carriers have been used to enhance permeation, reduce rapid renal clearance, and avoid burst drug release of chemotherapeutic drugs. ${ }^{11}$ Poloxamer 188, also known as Pluronic F68 (F68), is a block copolymer that has been submit your manuscript Dovepress f cC. hereby accept the Terms. Non-commercial uses of the work are permitted without any further permission from Dove Medical Press Limited, provided the work is properly attributed. For permission for commercial use of this work, please see paragraphs 4.2 and 5 of our Terms (https://www.dovepress.com/terms.php). 
accepted as a pharmaceutical excipient by the British and US Pharmacopeia and approved by the US Food and Drug Administration for intravenous injection. ${ }^{9,12-14}$ According to published reports, hydrophobic drugs could be incorporated into F68-based micelles, which were used to deliver drugs to enhance their anticancer effect. ${ }^{14-16}$ For example, cholesterolcoupled F68 micelles could enhance the anticancer activity of cabazitaxel compared to a Tween 80 -based drug solution. ${ }^{14}$ However, F68 has a high critical micelle concentration (CMC) and a low drug loading (DL) capacity, resulting in poor dilution stability of the micelles. ${ }^{14,17}$ In order to overcome the drawbacks of F68 micelles, a number of methods have been proposed, including appropriate chemical modifications and mixed micelles. ${ }^{13,18}$

Vitamin E succinate ( $\alpha$-tocopheryl succinate, VES), a hydrophobic vitamin analog of vitamin E, displays hydrophobicity mainly due to the relatively bulky lipophilic portion in its structure, which makes it more applicable for drug solubilization. ${ }^{19,20}$ It was reported that VES-based micelles, including VES-modified Pluronic P123 micelles and VES-modified chitosan micelles, could enhance anticancer activity. ${ }^{20,21}$ In this study, the amphipathic polymer formed by the conjunction of F68 with VES was developed to enhance drug encapsulation. We synthesized the F68-VES polymer and prepared MIT-loaded F68-VES (F68-VES/ MIT) micelles via self-assembly under aqueous condition (Figure 1A). The features of F68-VES/MIT micelles were further determined by dynamic light scattering (DLS) and transmission electron microscopy (TEM). Besides, F68-VES micelles had a low CMC value of $3.311 \mathrm{mg} / \mathrm{L}$ and exhibited favorable stability even in the presence of fetal bovine serum (FBS). As compared to free MIT, F68-VES/MIT micelles had a stronger cytotoxic and pro-apoptotic effect on MDAMB-231 cells (a human breast cancer line). In addition,

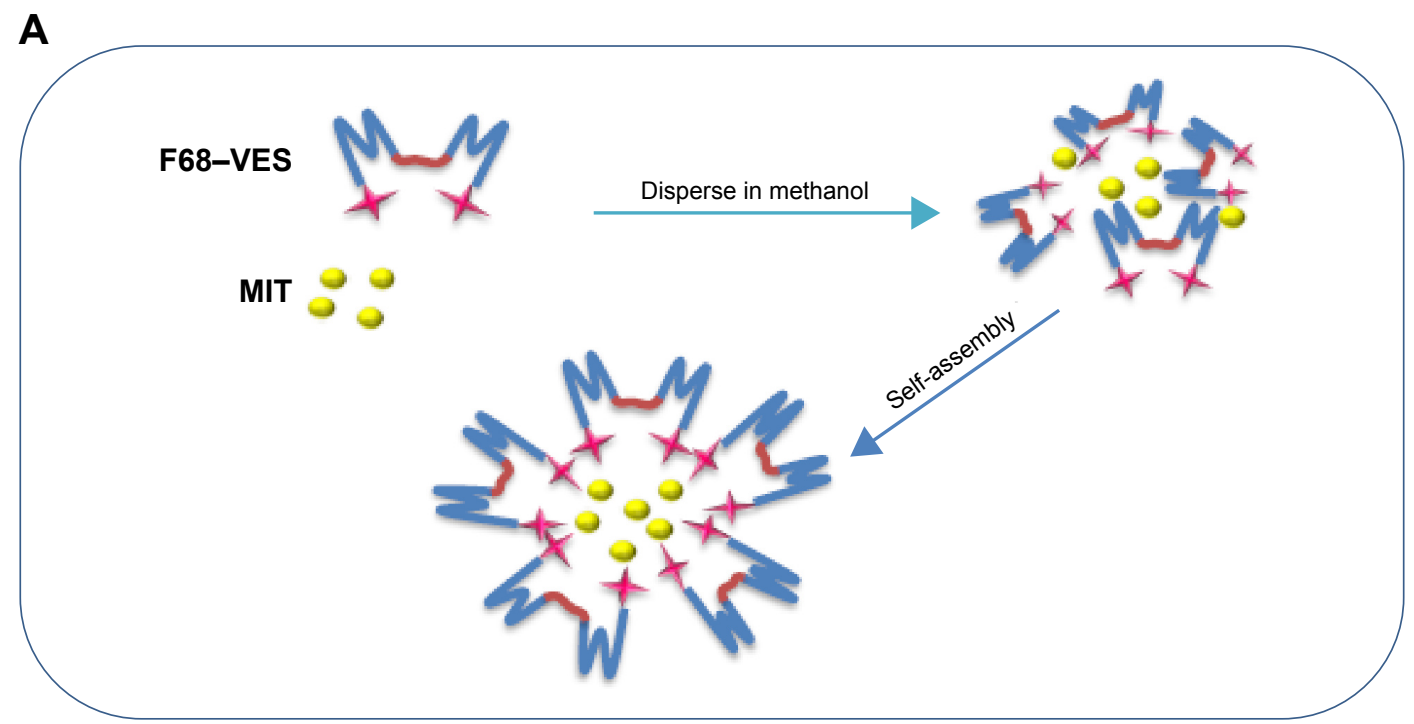

B
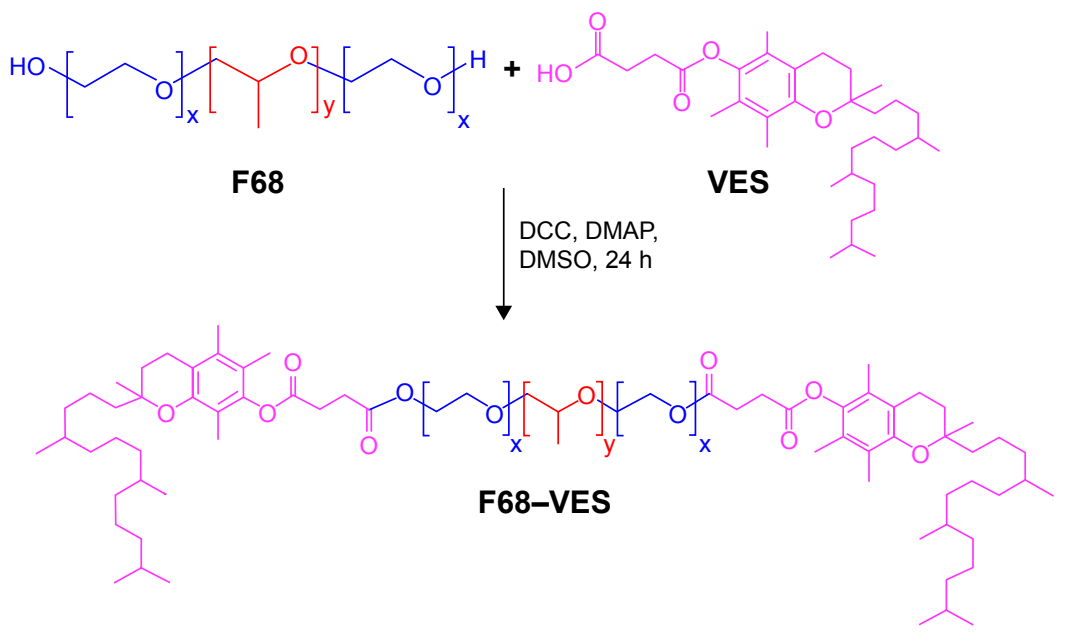

Figure I Illustration of the synthesis and preparation of MIT-loaded F68-VES (F68-VES/MIT) micelles.

Notes: (A) Preparation of F68-VES/MIT micelles. (B) Synthesis of F68-VES polymer.

Abbreviations: F68, Pluronic F68; VES, vitamin E succinate; F68-VES/MIT micelles, mitoxantrone-loaded Pluronic F68-conjugated vitamin E succinate polymer micelles; F68-VES, Pluronic F68-conjugated vitamin E succinate; DCC, dicyclohexylcarbodiimide; DMAP, 4-dimethylaminopyridine; DMSO, dimethyl sulfoxide; MIT, mitoxantrone. 
we investigated the cellular uptake via autofluorescence of MIT to observe the difference between F68-VES/MIT micelles and free MIT. The results showed that F68-VES/ MIT micelles had higher cellular uptake compared to free MIT in MDA-MB-231 cells. On the whole, F68-VES/MIT micelles, with efficient incorporation and controlled release of MIT, have the advantages of outstanding stability, better DL capacity, and higher cellular uptake, compared to free MIT.

\section{Materials and methods Materials}

Pluronic F68 (molecular weight=8,350) was purchased from BASF SE (Ludwigshafen, Germany). VES was purchased from Aladdin Industrial Corporation (Shanghai, People's Republic of China). MIT was supplied by Meilun Biological Technology Co., Ltd. (Dalian, People's Republic of China). Dicyclohexylcarbodiimide and 4-dimethylaminopyridine were purchased from GL Biochem (Shanghai, People's Republic of China). Millipore water was prepared by a Milli-Q Plus System (Merck Millipore Co., Billerica, MA, USA). All chemicals were of analytical grade.

Dulbecco's Modified Eagle's Medium (DMEM), FBS, phosphate-buffered saline (PBS), penicillin-streptomycin, and $0.25 \%(\mathrm{w} / \mathrm{v})$ trypsin/1 mM EDTA were obtained from Thermo Fisher Scientific (Waltham, MA, USA). 3-[4,5-dimethyl-2-thiazolyl]-2,5-diphenyl tetrazolium bromide (MTT) was purchased from Sigma-Aldrich (St Louis, MO, USA). Hoechst 33342 and propidium iodide (PI) were purchased from Thermo Fisher Scientific.

\section{Synthesis and characterization of F68-VES polymer}

The F68-VES polymer was synthesized by conjugating VES to the terminal hydroxyl groups of F68. In brief, F68 (10 mmol), VES (25 mmol), dicyclohexylcarbodiimide (30 mmol), and 4-dimethylaminopyridine (30 mmol) were dissolved in dry dimethyl sulfoxide (DMSO, $20 \mathrm{~mL}$ ) and stirred well at room temperature under nitrogen protection for 24 hours. The resulting solution was dialyzed (molecular weight cut-off at $3,500 \mathrm{Da}$ ) against DMSO to remove unreacted entities and further dialyzed against Millipore water to remove DMSO. The byproduct $N, N^{\prime}$-dicyclohexylurea in the dialysis fluid was removed by filtration, and the final product (F68-VES) was obtained by lyophilization.

\section{Characterization of F68-VES polymer}

The structure of F68-VES polymer was confirmed by ${ }^{1} \mathrm{H}$ nuclear magnetic resonance $\left({ }^{1} \mathrm{H} \mathrm{NMR}\right)$ spectroscopy and fourier transform infrared (FTIR) spectroscopy. F68-VES polymer was detected by ${ }^{1} \mathrm{H}$ NMR spectroscopy (Bruker Optik $\mathrm{GmbH}$, Ettlingen, Germany) at $400 \mathrm{MHz}$ using DMSO- $d_{6}$ as solvent. FTIR spectrophotometer (Nicolet, Hudson, NH, USA) was used to additionally demonstrate the structure of F68-VES in the absorbance range of $400-4,000 \mathrm{~cm}^{-1}$.

\section{Preparation of F68-VES/MIT micelles}

MIT-loaded F68-VES micelles were prepared by the solvent evaporation method as previously reported. ${ }^{22}$ Briefly, a mixture containing $15 \mathrm{mg}$ F68-VES polymer and $1 \mathrm{mg}$ MIT was dissolved in methanol. The solution was then added dropwise into distilled water with stirring for 6 hours at room temperature. The residual organic solvent was removed by vacuum evaporation. Finally, the F68-VES/MIT micelles were filtrated using a $0.45 \mu \mathrm{m}$ microfiltration membrane to remove undissolved materials. Blank F68-VES micelles were also prepared by the abovementioned method.

\section{Characterization of F68-VES/MIT micelles}

The average particle size and zeta potential of F68-VES/MIT micelles were measured by DLS with a Zetasizer Nano ZSP system (Malvern Instruments, Malvern, UK). Each sample was evenly dispersed and measured three times at $25^{\circ} \mathrm{C}$. The morphology of F68-VES/MIT micelles was characterized by transmission electron microscopy (TEM; Tecnai G20; FEI Company, OR, USA) with an accelerating voltage of $200 \mathrm{kV}$. The DL and encapsulation efficiency (EE) of MIT in the drug-loaded micelles were measured by Waters e2695 HPLC system equipped with a C18 reverse-phase liquid chromatography column $(250 \times 4.6 \mathrm{~mm})$. The mobile phase was methanol $/ 0.25 \%$ acetic acid (50/50, v/v). The flow velocity was $1.0 \mathrm{~mL} / \mathrm{min}$ at the maximum absorption wavelength of $670 \mathrm{~nm}$. The polymeric shells were disrupted by adding methanol before HPLC analysis and the EE (\%) and DL (\%) of MIT in the micelles were calculated by using the following equations:

$$
\begin{gathered}
\text { DL }(\%)=\frac{\text { Weight of the drug in micelles }}{\text { Weight of the materials and drugs }} \times 100 \% \\
\text { EE }(\%)=\frac{\text { Weight of the drug in micelles }}{\text { Weight of the feeding drugs }} \times 100 \%
\end{gathered}
$$

\section{In vitro drug release of MIT from micelles}

Dialysis was used to investigate the in vitro MIT release from F68-VES/MIT micelles. Free MIT was dissolved in 
methanol as control. The release medium was composed of PBS solution ( $\mathrm{pH} 7.4$ ) containing $0.1 \%(\mathrm{w} / \mathrm{v})$ Tween 80 . Two milliliters of F68-VES/MIT micelle solution or free MIT solution with equivalent drug concentration $(0.1 \mathrm{mg} / \mathrm{mL})$ was added to the dialysis tubes with a molecular weight cut-off at 3,500 Da. The dialysis tubes were immersed into $40 \mathrm{~mL}$ release medium and incubated in a shaking water bath at $37^{\circ} \mathrm{C}$ with stirring at $100 \mathrm{rpm}$. During predetermined intervals, $1 \mathrm{~mL}$ of release medium was taken out and the same volume of fresh medium was refilled into the identical dialysis system. Equal volume of methanol was used to dilute the collected release medium, which was filtered by a $0.45 \mu \mathrm{m}$ microfiltration membrane. The MIT content in the collected release medium was analyzed by HPLC, as mentioned earlier. The drug release experiments were performed in triplicate.

\section{The stability of micelles}

$\mathrm{CMC}$ is a vital parameter reflecting the stability of micelles in the medium. In this study, the CMC of F68-VES micelles was analyzed by using pyrene as a fluorescence probe. ${ }^{22,23}$ The F68-VES micellar solutions at concentrations ranging from $3 \times 10^{-5} \mathrm{mg} / \mathrm{mL}$ to $1 \mathrm{mg} / \mathrm{mL}$ were prepared with pyrene at $6 \times 10^{-7} \mathrm{M}$. Pyrene fluorescence in the micellar solutions was measured by a fluorescence spectrometer (Lumina; Thermo Fisher Scientific) with an excitation wavelength of $339 \mathrm{~nm}$ and an emission wavelength range between $360 \mathrm{~nm}$ and $450 \mathrm{~nm}$. The excitation spectra were scanned to analyze the relationship between fluorescence intensity ratio of pyrene $I_{373} / I_{384}$ and the micelle concentration. The fluorescence intensity ratio of pyrene $I_{373} / I_{384}$ was analyzed as a logarithm function of the F68-VES micellar concentration. The fluorescence intensity ratio of pyrene $I_{373} / I_{384}$ from the excitation spectra was analyzed as a function of the micelle concentration. ${ }^{23}$ Additionally, we applied the well-known Tyndall phenomenon to further estimate the stability of F68-VES micelles. A stable micellar solution should show a visible light beam when it is irradiated by a laser pointer. ${ }^{24}$ The initial F68-VES micellar solution was diluted with distilled water in sequence and the solutions with different concentrations were illuminated by a red laser. Micellar solutions at concentrations ranging from $0.76 \times 10^{-3} \mathrm{mg} / \mathrm{mL}$ to $1.52 \mathrm{mg} / \mathrm{mL}$ were prepared at room temperature for this study.

In order to simulate the stability of micelles in blood circulation through in vitro tests, we measured the particle size of F68-VES/MIT micelles by DLS in the presence of different FBS concentrations. ${ }^{25}$ Briefly, F68-VES/MIT micellar solutions containing $20 \%, 30 \%, 40 \%$, and $50 \%$ FBS were prepared and incubated at $37^{\circ} \mathrm{C}$ for different time intervals.
At scheduled time points, the appearance of micellar solutions was observed and the particle size was measured.

\section{Cell culture}

The human breast cancer cell lines MDA-MB-231 and MCF-7 were obtained from American Type Culture Collection (Manassas, VA, USA). The cells were cultured in DMEM containing $10 \%(\mathrm{v} / \mathrm{v})$ heat-inactivated FBS and antibiotics $(100 \mathrm{U} / \mathrm{mL}$ penicillin and $100 \mu \mathrm{g} / \mathrm{mL}$ streptomycin) at $37^{\circ} \mathrm{C}$ under $5 \% \mathrm{CO}_{2}$. No ethical committee approval was required for this set of experiments because the experiments were performed on commercially available cell lines and the China Academy of Chinese Medical Sciences/ University of Macau human subjects protection program/ ethical review board deemed it exempt.

\section{Cytotoxicity assay}

In vitro cytotoxicity of F68-VES/MIT micelles was determined using MTT assay. MCF-7 and MDA-MB-231 cells were seeded in 96-well plates at a density of 5,000 cells per well and cultured in $100 \mu \mathrm{L}$ DMEM medium overnight. The cells were then treated with free MIT and F68-VES/MIT micelles at concentrations ranging from $0.25 \mu \mathrm{M}$ to $4 \mu \mathrm{M}$ for 24 hours and 48 hours, respectively. Untreated cells and cells treated with blank F68-VES micelles at equal volumes of F68-VES/MIT micelles were served as the control. After incubation, the medium was discarded and replaced by culture medium containing $1 \mathrm{mg} / \mathrm{mL}$ MTT and incubated for additional 4 hours before $100 \mu \mathrm{L}$ DMSO was added to each well to allow the dissolution of formazan. The resulting absorbance, which represented the cell viability, was recorded by a microplate reader (SpectaMax M5; Molecular Devices LLC, Sunnyvale, CA, USA) at $570 \mathrm{~nm}$.

\section{Apoptosis assay}

The Annexin V-FITC/PI assay was used to detect apoptotic cells according to the manufacturer's instruction. To investigate the apoptotic effect of F68-VES/MIT micelles on cancer cells, MDA-MB-231 cells were plated in six-well plates at a density of $2 \times 10^{5}$ cells/well. The cells were treated with $2 \mu \mathrm{M}$ of free MIT solution or F68-VES/MIT micelles for 24 hours. After the incubation period, both attached and unattached cells were collected and suspended in the binding buffer-dilute Annexin-FITC solution, allowing incubation in the dark for 15 minutes. Then, PI solution was added before flow cytometry analysis.

To observe morphologic change of MDA-MB-231 cells, Hoechst 33342 staining assay was carried out. MDA-MB-231 cells were plated into 96-well plates the day before being treated 
with free MIT and F68-VES/MIT micelles at an equivalent MIT concentration of $2 \mu \mathrm{M}$. After treatment for 24 hours, the medium was removed and cells were fixed with $4 \%$ paraformaldehyde (PFA) for 10 minutes. The cells were then washed twice with PBS to remove the free drugs and stained with Hoechst $33342(10 \mu \mathrm{g} / \mathrm{mL})$ at room temperature for 15 minutes later. Cells were observed and imaged by IN Cell Analyzer 2000 (GE Healthcare Bio-Sciences Corp., Piscataway, NJ, USA).

\section{Cell uptake study}

The cellular uptake efficiency of F68-VES/MIT micelles was monitored by flow cytometry. Briefly, $8 \times 10^{5}$ MDAMB-231 cells were plated into 12-well plates. After overnight incubation, cells were treated with $2 \mu \mathrm{M}$ free MIT or F68-VES/MIT and incubated at $37^{\circ} \mathrm{C}$ for various time periods ( 1 hour, 3 hours, and 6 hours). Then, cells were collected by centrifugation and washed twice to remove the free drugs. By taking advantage of the fluorescence emitted by MIT, cellular uptake of free MIT of F68-VES/MIT micelles was analyzed by flow cytometry.

The cellular uptake of free MIT and F68-VES/MIT in MDA-MB-231 cells was also imaged by using the IN Cell Analyzer 2000. After being seeded into 96-well plates with a density of $8 \times 10^{3}$ cell/well overnight, MDA-MB-231 cells were treated with $2 \mu \mathrm{M}$ free MIT or F68-VES/MIT micelles for 6 hours in the incubator. The incubation was terminated by removing the medium and fixing the cells in 4\% PFA for 10 minutes, followed by washing the cells with PBS twice and staining them with Hoechst $33342(10 \mu \mathrm{g} / \mathrm{mL})$ for 10 minutes. The cells were observed by fluorescent $\mathrm{Cy} 5$ and 4',6-diamidino-2-phenylindole channels.

\section{Statistical analysis}

Statistical analysis was performed with GraphPad Prism 5 software (GraphPad Software, Inc., La Jolla, CA, USA) based on at least three separate experiments. Statistical significance was analyzed by one-way ANOVA or Student's $t$-test. $P$-value $<0.05$ was considered as statistically significant.

\section{Results \\ Synthesis and characterization of F68-VES polymer}

A novel amphiphilic F68-VES polymer was synthesized via the esterification reaction; Figure 1B showed the synthetic route of F68-VES polymer. The hydroxyl group of VES reacted with the carboxyl group at the end of F68 to form the F68-VES polymer. ${ }^{1} \mathrm{H}$ NMR and FTIR techniques were used to demonstrate the successful synthesis of F68-VES polymer. The ${ }^{1} \mathrm{H}$ NMR spectrum of F68-VES polymer was shown in Figure 2. Figure 2A-C presented the ${ }^{1} \mathrm{H}$ NMR spectrum of F68, VES and F68-VES, respectively. The typical peaks of polypropylene oxide (PPO) in F68 were observed in the chemical shift ranging from $1.0 \mathrm{ppm}$ to $3.5 \mathrm{ppm}$, including peak e $(\delta=1.37 \mathrm{ppm})$ for $\mathrm{CH}_{3}$ groups, peak c $(\delta=3.38 \mathrm{ppm})$

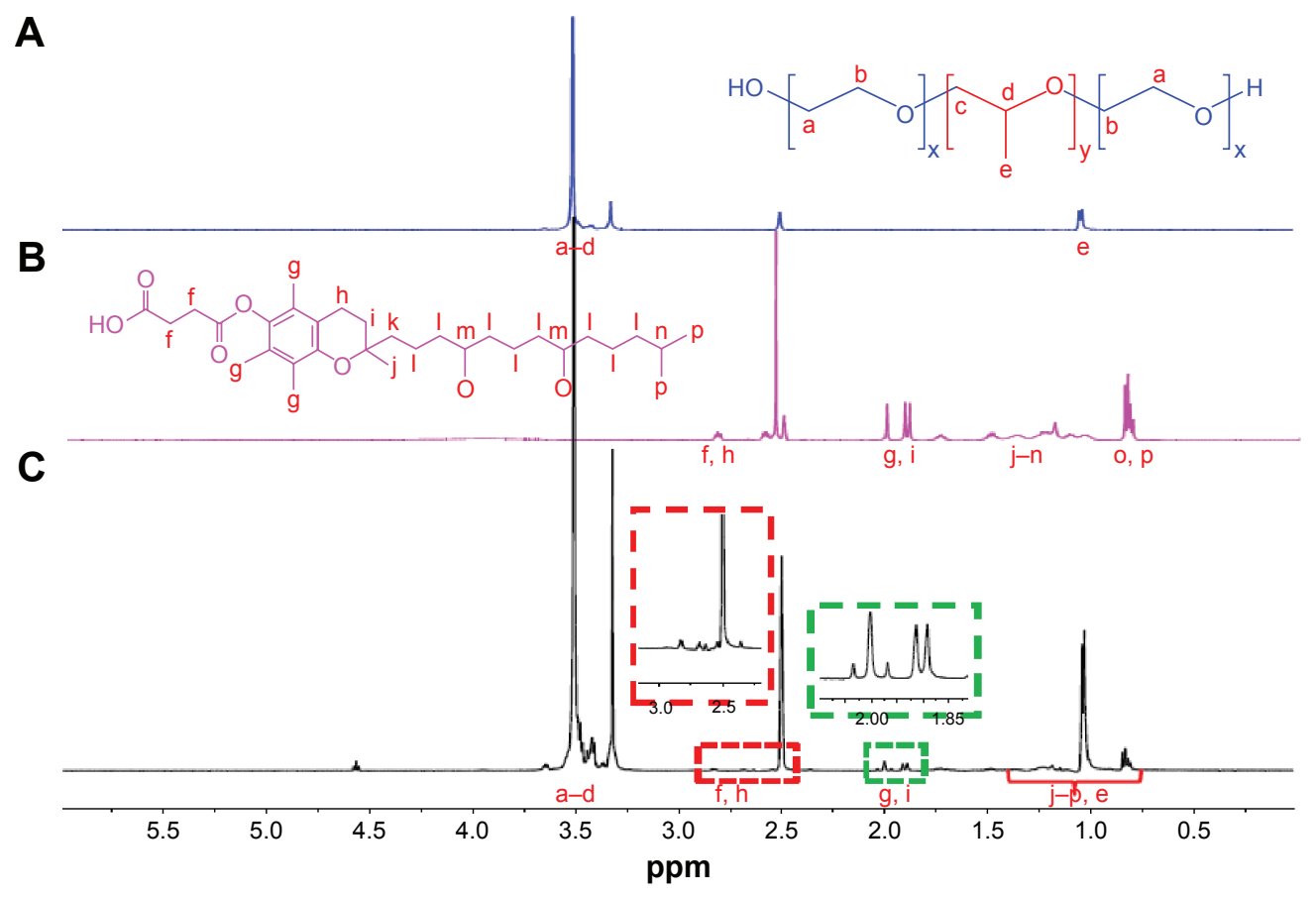

Figure 2 'H NMR spectrum of F68-VES polymer.

Notes: (A) F68. (B) VES. (C) F68-VES.

Abbreviations: 'H NMR, 'H nuclear magnetic resonance; F68, Pluronic F68; VES, vitamin E succinate; F68-VES, Pluronic F68-conjugated vitamin E succinate. 
for $\mathrm{CH}_{2}$ groups, and peak d ( $\left.\delta=3.34 \mathrm{ppm}\right)$ for $\mathrm{CH}$ groups. Other strong peaks ( $\mathrm{a}$ and $\mathrm{b}$ ) were the $\mathrm{CH}_{2}$ groups of polyethylene oxide (PEO) in F68 with a chemical shift near $3.6 \mathrm{ppm}$. Simultaneously, we discovered typical signals for VES, including peak $\mathrm{f}(\delta=2.70-2.85 \mathrm{ppm})$ for the $\mathrm{CH}_{2}$ group close to carboxyl group, peak $\mathrm{g}(\delta=2.08 \mathrm{ppm})$ for the $\mathrm{CH}_{3}$ group on the benzene ring and peak $\mathrm{h}(\delta=2.70-2.85 \mathrm{ppm})$ for the $\mathrm{CH}_{2}$ group on the heterocyclic ring. The peaks $1, \mathrm{~m}, \mathrm{o}-\mathrm{p}$ at $1.25 \mathrm{ppm}, 1.62 \mathrm{ppm}$, and 0.91-0.96 ppm belonged to the repeating units of $-\mathrm{CH}_{2},-\mathrm{CH}$, and $-\mathrm{CH}_{3}$ in VES, respectively. Moreover, the structure of F68-VES polymer was verified by FTIR (Figure 3). The vibration peak associated with the ester bond formed by the reaction of the carboxyl group in F68 and the hydroxyl group in VES was at $1,713 \mathrm{~cm}^{-1}$. In short, ${ }^{1} \mathrm{H}$ NMR and FTIR spectra indicated that the F68-VES polymer was successfully synthesized.

\section{Characterization of F68-VES/MIT micelles}

For the purpose of better understanding the characteristics of MIT-loaded F68-VES micelles, their particle size, zeta potential, morphology, DL, and EE were evaluated in this study. The particle sizes of the blank micelles and F68-VES/MIT micelles were tested by DLS, and their mean diameters were found to be $137.77 \pm 3.81 \mathrm{~nm}$ and $184.33 \pm 6.53 \mathrm{~nm}$, respectively (Figure 4A). Both MIT-loaded micelles and blank micelles had the narrow size distribution (PDI: $0.06 \pm 0.03$ for F68-VES/MIT micelles and $0.13 \pm 0.02$ for blank micelles). Compared to blank micelles, F68-VES/MIT micelles showed no obvious increase in particle size. It has been reported that polymeric micelles with particle size in the range of $10-200 \mathrm{~nm}$ could promote drug accumulation in tumor sites

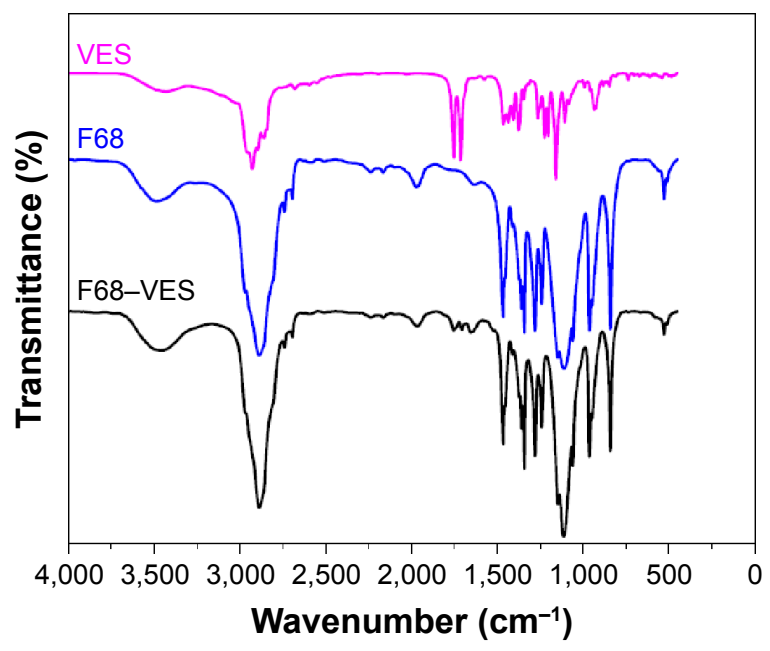

Figure 3 FTIR spectrum of F68-VES polymer.

Abbreviations: F68, Pluronic F68; VES, vitamin E succinate; F68-VES, Pluronic F68conjugated vitamin E succinate; FTIR, fourier transform infrared. on account of enhanced permeability and retention effect. ${ }^{26}$ Thus, the nanometer size and the narrow size distribution of F68-VES/MIT micelles might be suitable for accumulation at the tumor site and would not be immediately eliminated by the reticuloendothelial system. ${ }^{27}$ According to various reports, the low absolute value of zeta potential was associated with insufficient electric repulsion among particles, which would lead to aggregation. ${ }^{15,28}$ In this study, a high absolute zeta potential of $-32.67 \pm 0.87 \mathrm{mV}$ for the F68-VES/ MIT micelles (Figure 4B) was observed, which might indicate the uniform distribution of the particles.

The TEM images showed that F68-VES/MIT micelles had homogeneous, spherical shapes and smooth edges without aggregation (Figure 4C), demonstrating that they maintained the integrity of their structure. The diameters of F68-VES/MIT micelles obtained from the TEM image matched well with those measured by DLS. Moreover, the EE and DL of F68-VES/MIT micelles measured by HPLC were $91.88 \% \pm 2.20 \%$ and $5.85 \% \pm 0.89 \%$, respectively, revealing the high DL capacity of F68-VES micelles. Therefore, F68-VES micelles could effectively encapsulate MIT with high stability and integrity of the structure.

\section{In vitro drug release of MIT from micelles}

The in vitro drug release behavior of free MIT and F68-VES/ MIT micelles was investigated under sink conditions via the dialysis method. In Figure 4D, we could clearly see that the cumulative release of MIT from the polymer micelles reached $\sim 30 \%$ at 4 hours, which was much less than that of free MIT solution at $37^{\circ} \mathrm{C}$. Approximately $70 \%$ of MIT was released from the free MIT solution after 8 hours, and 80\% after 48 hours, while only $40 \%$ and $55 \%$ of MIT were released from the polymer micelle at 8 hours and 48 hours, respectively. The MIT release behavior reflected that the drug was incorporated into the hydrophobic core of the micelles and was slowly released even under sink conditions. ${ }^{29}$ Collectively, the results revealed that MIT-loaded F68-VES micelles had sustained release ability, which was beneficial for keeping an effective concentration during the treatment.

\section{The stability of micelles}

$\mathrm{CMC}$ is a common index to demonstrate the stability and physical properties of micelles. ${ }^{22}$ In this study, the CMC of F68-VES micelles was measured by using pyrene as the fluorescent probe. Pyrene, with the structure of condensed aromatics, is sensitive to polarity. The changes of fluorescence intensity of pyrene were measured by fluorescence spectrometry as a function of increasing concentrations of copolymers, and the dramatic increase in fluorescence 

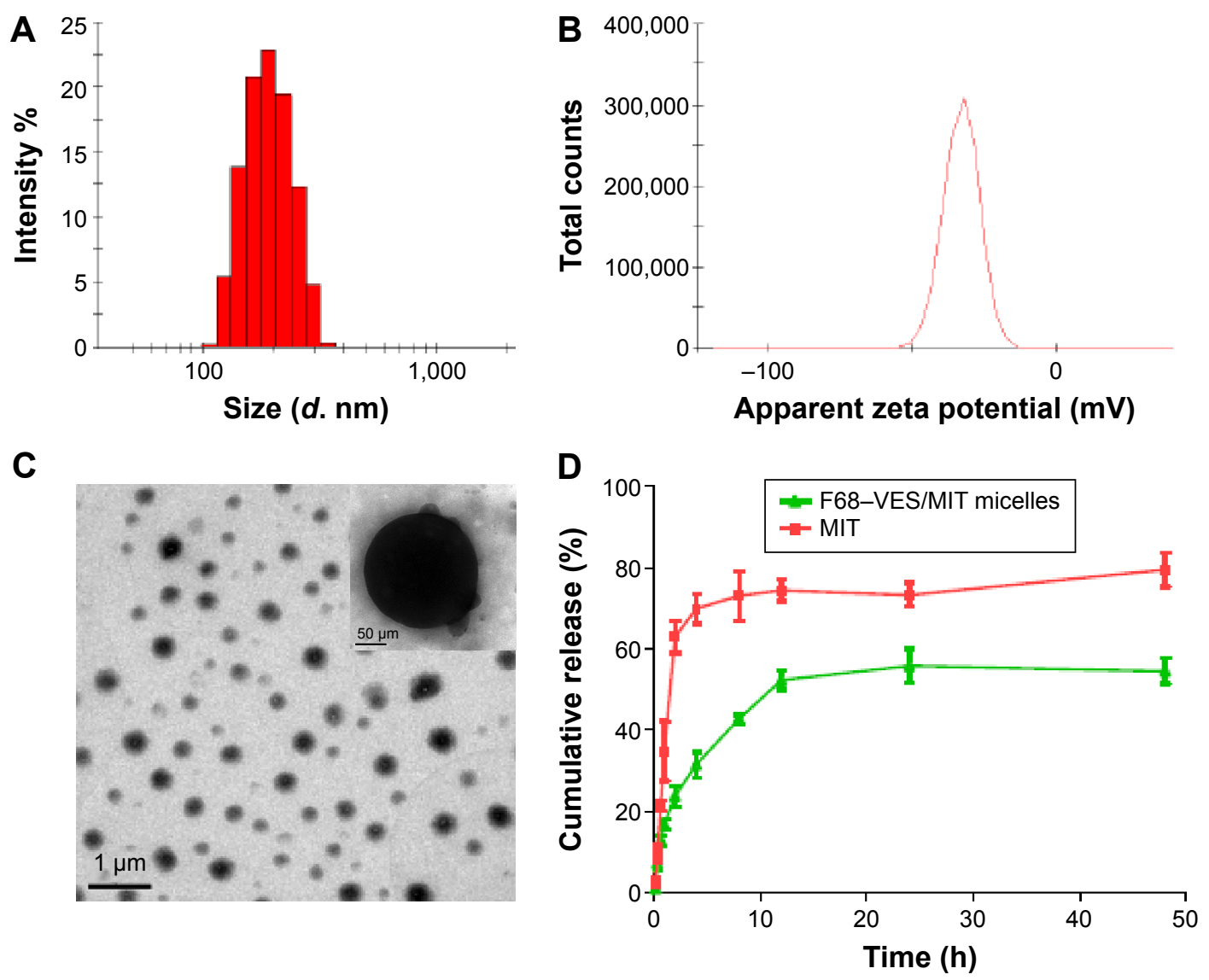

Figure 4 Characterization of F68-VES/MIT micelles.

Notes: (A) Size distribution of F68-VES/MIT micelles. (B) Zeta potential of F68-VES/MIT micelles. (C) TEM images of F68-VES/MIT micelles. (D) In vitro accumulative release of MIT from free MIT solution and F68-VES/MIT micelles. Error bar represents the standard deviation value of three experiments.

Abbreviations: F68-VES/MIT micelles, mitoxantrone-loaded Pluronic F68-conjugated vitamin E succinate polymer micelles; MIT, mitoxantrone; TEM, transmission electron microscopy.

intensity showed micelle formation. The CMC value of F68-VES micelles was $\sim 3.311 \mathrm{mg} / \mathrm{L}$ (Figure $5 \mathrm{~A}$ ), which illustrated that F68-VES micelles were stable with a low $\mathrm{CMC}$ value and had a great resistance to dilution with integrated structure in body blood circulation. Besides, the classic Tyndall effect was used to estimate the stability of F68-VES micelles. A series of polymer micellar solutions with different concentrations was prepared in this study, and the distinct red light could be seen when these micellar solutions were illuminated by a red laser beam. As shown in Figure 5B, it was clear that all F68-VES micellar solutions showed a clear light beam under the red laser irradiation until the micelle concentration was $<0.0076 \mathrm{mg} / \mathrm{mL}$, which was represented by the sample S6 in Figure 5B. However, sample $\mathrm{S} 7(0.0015 \mathrm{mg} / \mathrm{mL})$ with a distinctly darker light than $\mathrm{S} 6$ was almost close to the brightness of water. The low CMC value of $3.311 \mathrm{mg} / \mathrm{L}$ could ensure F68-VES micelles to maintain structural integrity under diluted conditions, which matched the results of Tyndall phenomenon.
The in vitro colloidal stability of F68-VES micelles was estimated in the presence of FBS. F68-VES micelles were diluted in water containing $20 \%, 30 \%, 40 \%$, and $50 \%$ FBS at $37^{\circ} \mathrm{C}$, and the hydrodynamic diameters were measured by DLS at different times. As shown in Figure 5C, the particle sizes of F68-VES micelles containing different FBS concentrations were stable without sharp changes as time increased up to 24 hours. When the FBS was $50 \%$, the change in the hydrodynamic size of the polymer micelles was small compared to the original size, which was $\sim 0.7$-fold of the initial diameter after 24 hours of incubation with FBS at $37^{\circ} \mathrm{C}$. In spite of the size change, the particles still exhibited good dispersion without visible particle precipitation (Figure 5D).

\section{In vitro cytotoxicity of F68-VES/MIT micelles}

With MTT assay, the growth inhibition of breast cancer MCF-7 and MDA-MB-231 cell lines was compared between F68-VES/MIT micelles and free MIT. Both MCF-7 and MDAMB-231 cells showed more cytotoxicity to F68-VES/MIT 
A
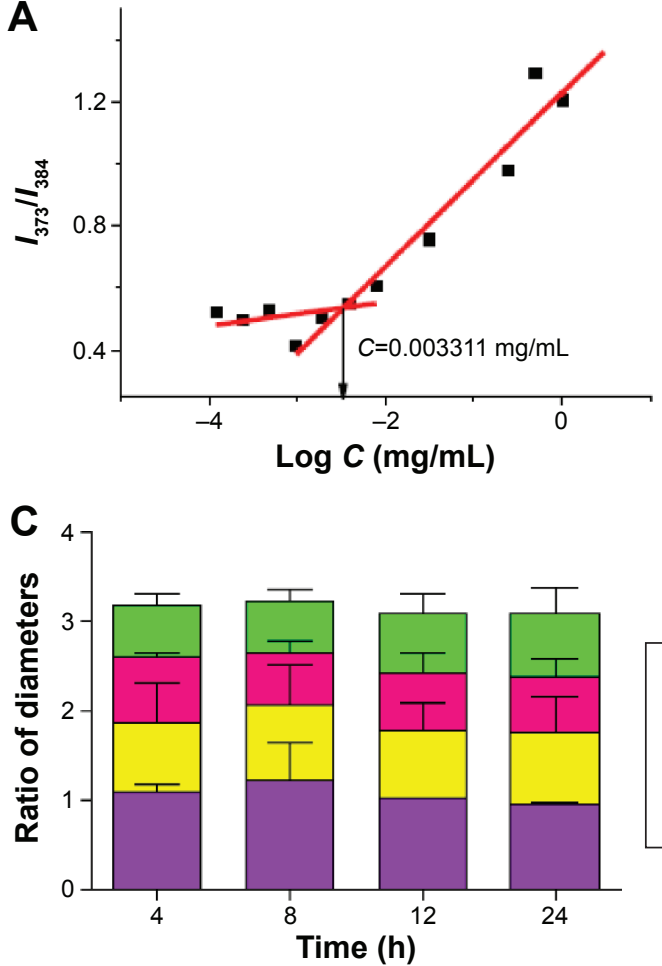

B
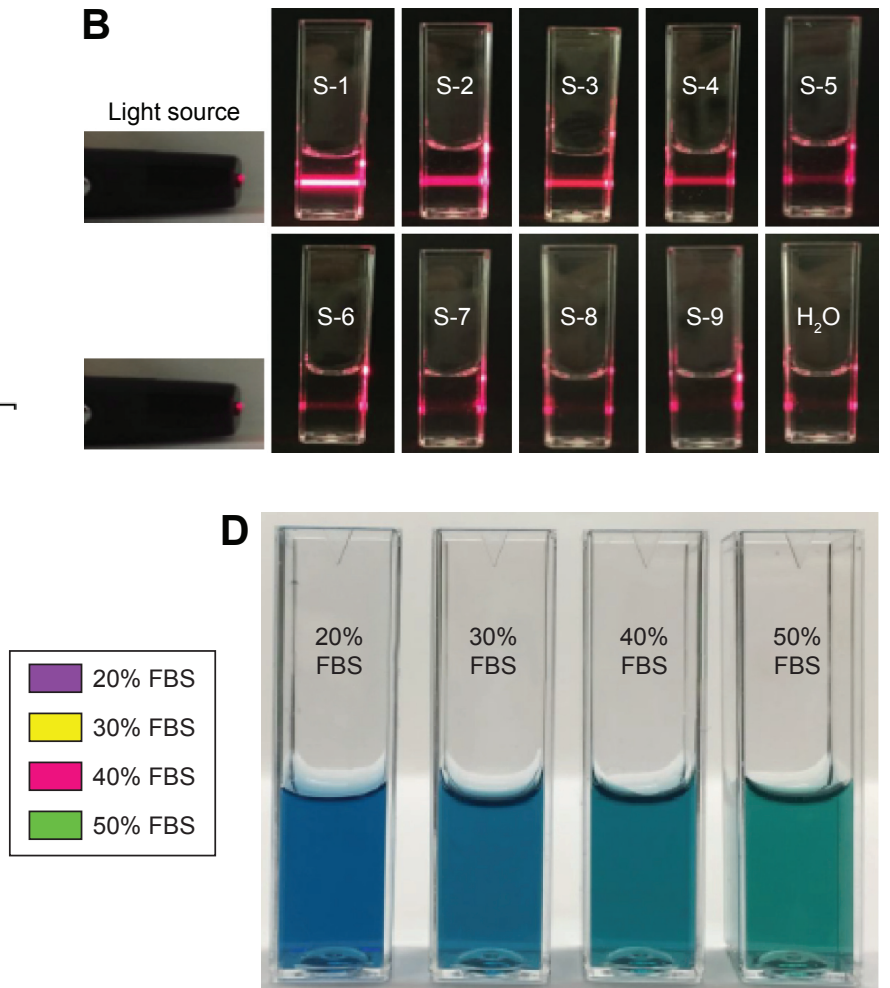

Figure 5 Test results of the stability of micelles.

Notes: (A) Critical micelle concentration (CMC) of blank F68-VES micelles using pyrene as a fluorescence probe. The arrow shows the value of CMC. (B) Images of blank F68-VES micellar solutions under the irradiation of red laser at different concentrations (s- I: $1.52 \mathrm{mg} / \mathrm{mL} ; \mathrm{s}-2: 7.60 \times 10^{-1} \mathrm{mg} / \mathrm{mL} ; \mathrm{s}-3: 1.52 \times 10^{-1} \mathrm{mg} / \mathrm{mL} ; \mathrm{s}-4: 7.60 \times 10^{-2} \mathrm{mg} /$ $\mathrm{mL}$; s-5: $1.52 \times 10^{-2} \mathrm{mg} / \mathrm{mL}$; s-6: $7.60 \times 10^{-3} \mathrm{mg} / \mathrm{mL}$; s-7: $1.52 \times 10^{-3} \mathrm{mg} / \mathrm{mL} ; \mathrm{s}-8: 7.60 \times 10^{-4} \mathrm{mg} / \mathrm{mL}$; s-9: $\left.1.52 \times 10^{-4} \mathrm{mg} / \mathrm{mL}\right)$. (C) Time-dependent colloidal stability of F68-VES/ MIT micelles in water containing $20 \%, 30 \%, 40 \%$ and $50 \% \mathrm{FBS}$ at $37^{\circ} \mathrm{C}$. The ratio of diameters is the one between the time-dependent hydrodynamic diameter and the initial hydrodynamic diameter in water. (D) Photograph of F68-VES/MIT micelles after incubation with $20 \%, 30 \%, 40 \%$ and $50 \%$ FBS at $37{ }^{\circ} \mathrm{C}$ for 24 hours. The error bar represents the standard deviation value of three experiments.

Abbreviations: F68-VES/MIT micelles, mitoxantrone-loaded Pluronic F68-conjugated vitamin E succinate polymer micelles; MIT, mitoxantrone; F68-VES, Pluronic F68conjugated vitamin E succinate; CMC, critical micelle concentration; FBS, fetal bovine serum; h, hours.

micelles than free MIT. The inhibition efficiency of both F68-VES/MIT micelles and free MIT increased as the inhibition time increased. The 24-hour half maximal inhibitory concentration $\left(\mathrm{IC}_{50}\right)$ values of $\mathrm{F} 68-\mathrm{VES} / \mathrm{MIT}$ micelles and free MIT on MCF-7 cells were $1.71 \mu \mathrm{M}$ and $2.79 \mu \mathrm{M}$, respectively. The 48-hour $\mathrm{IC}_{50}$ values of free MIT and F68-VES/MIT micelles decreased to $0.62 \mu \mathrm{M}$ and $0.48 \mu \mathrm{M}$ respectively. Noticeably, in MDA-MB-231 cells, the $\mathrm{IC}_{50}$ values of F68-VES/MIT micelles were lower than those of free MIT at 24-hour and 48-hour treatment time points, which were $1.64 \mu \mathrm{M}$ versus $1.94 \mu \mathrm{M}$ (24 hours) and $0.47 \mu \mathrm{M}$ versus $0.59 \mu \mathrm{M}$ (48 hours), respectively (Figure 6). Meanwhile, the cytotoxicity of blank micelles was assessed, and the result showed that the survival rates of the two cell lines reached over $90 \%$ after incubation with blank micelles of the same volume of the drug-loaded group for 24 hours and 48 hours, indicating that blank F68-VES micelles had negligible cytotoxic effect on MCF-7 and MDA-MB-231 cells. These results showed that F68-VES/MIT micelles exerted significantly enhanced cytotoxicity on MCF-7 cells and MDA-MB-231 cells.

\section{Apoptotic effect of F68-VES/MIT micelles on MDA-MB-23 I cells}

MIT is one of the commonly used chemotherapeutic agents for the treatment of acute myeloid leukemia, metastatic breast cancer, and non-Hodgkin's lymphoma, whose mechanisms of action are concerned with the inhibition of topoisomerase II, DNA intercalation, and disruption of DNA repair. ${ }^{2}$ Given that F68-VES/MIT micelles elicited cell death, we performed apoptosis assay with AnnexinV flow cytometry to evaluate the apoptotic effect of F68-VES/MIT micelles. This assay demonstrated that free MIT and F68-VES/MIT micelles showed a significant effect with apoptotic rates of $38.9 \%$ and $60.8 \%$, respectively (Figure 7). In other words, the apoptotic rate of F68-VES/MIT micelles was 1.56-fold higher than that of free MIT. The result was further confirmed by cell nuclear morphology observation. After staining with Hoechst 33342 , MDA-MB-231 cell nuclei presented as weak homogeneous blue were observed in cells untreated or treated with blank micelles, while bright chromatin condensation and nuclear fragmentation were identified in cells treated with $2 \mu \mathrm{M}$ free 
MCF-7 $24 \mathrm{~h}$

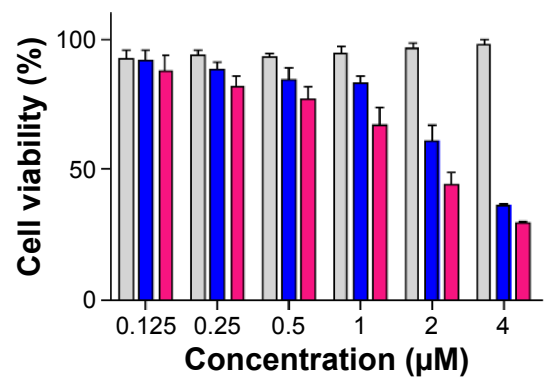

MDA-MB-231 $24 \mathrm{~h}$

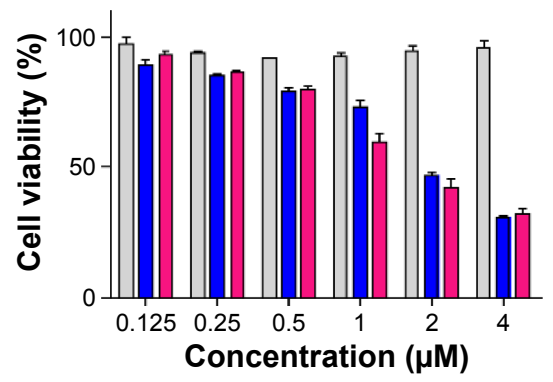

MCF-7 $48 \mathrm{~h}$

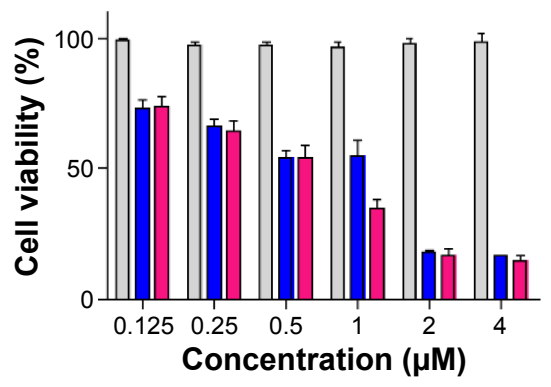

MDA-MB-231 $48 \mathrm{~h}$

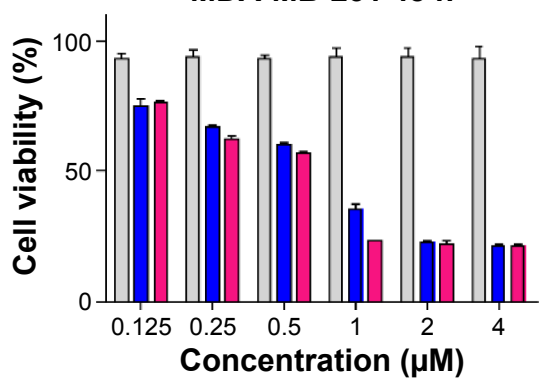

$\square$ Blank $\square$ Free MIT $\square$ MIT-loaded micelles

Figure 6 Cell viability of MCF-7 and MDA-MB-23I cells treated with blank F68-VES micelles, free MIT solution, and F68-VES/MIT micelles for 24 hours and 48 hours. Note: Error bar represents the standard deviation value of three experiments.

Abbreviations: F68-VES/MIT micelles, mitoxantrone-loaded Pluronic F68-conjugated vitamin E succinate polymer micelles; F68-VES, Pluronic F68-conjugated vitamin E succinate; MIT, mitoxantrone; h, hours.

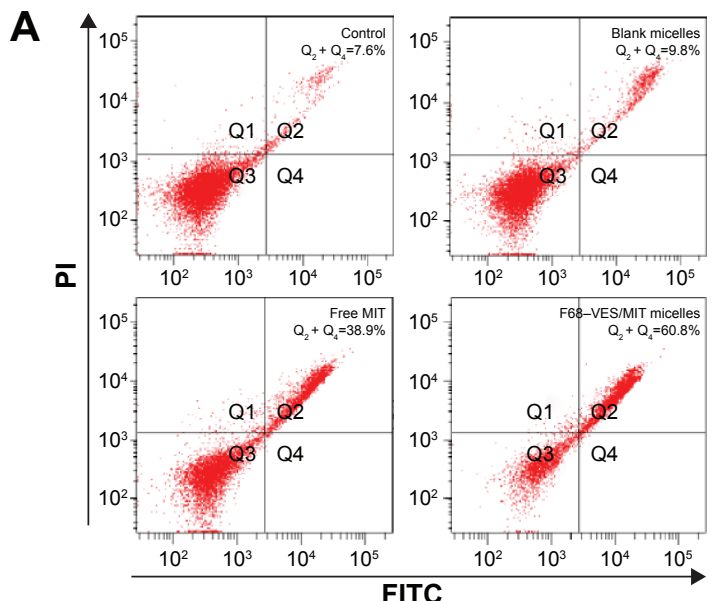

C

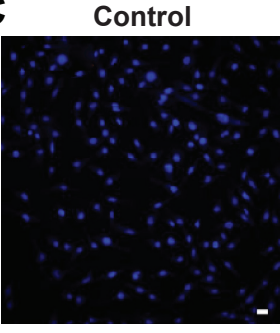

Blank micelles

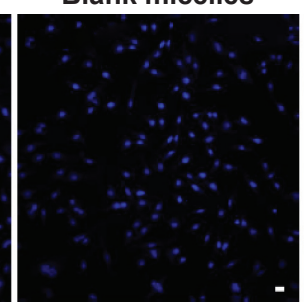

B

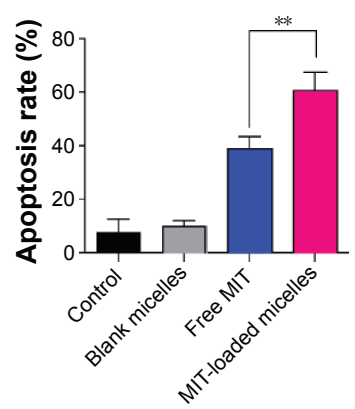

Free MIT

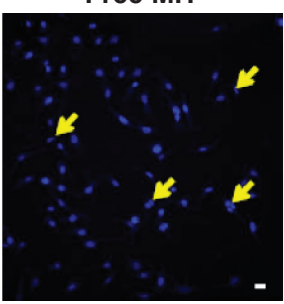

Figure 7 Apoptotic effect of F68-VES/MIT micelles on MDA-MB-23I cells.

Notes: (A) Cell apoptosis of MDA-MB-23I cells after treatment of different solutions (free MIT and MIT-loaded micelles) for 24 hours at MIT concentration of $2 \mu$ M. $Q_{1}$, $Q_{2}$, $Q_{3}$, and $Q_{4}$ phases correspondingly stand for necrotic cells, late apoptotic cells, live cells, and early apoptotic cells. (B) Apoptotic rates $\left(Q_{2}+Q_{4}\right)$ of cells with or without $M I T$ treatment are presented by bar graph. (C) Nuclear morphology of MDA-MB-23 I cells treated with free MIT solution or F68-VES/MIT micelles for 24 hours at MIT concentration of $2 \mu \mathrm{M}$. Untreated cells and cells treated with blank micelles served as controls. Cells were stained with Hochest 33342 to visualize nuclear morphology. Apoptotic cells are pointed out with arrows. Error bar represents the standard deviation value of three experiments. The scale bars correspond to $20 \mu \mathrm{m}$ in all the images. $* * P<0.0 \mathrm{I}$.

Abbreviations: MIT, mitoxantrone; F68-VES/MIT micelles, mitoxantrone-loaded Pluronic F68-conjugated vitamin E succinate polymer micelles; h, hours; PI, propidium iodide; FTIR, fourier transform infrared. 
MIT or F68-VES/MIT micelles. Of note, we found a higher apoptotic rate in the F68-VES/MIT micelles group than in free MIT group through nuclear morphology observation.

\section{Cellular uptake of MIT released from F68-VES/MIT micelles}

To confirm whether the enhanced cytotoxicity of F68-VES/ MIT micelles was related to the improved intracellular uptake of MIT, the cellular uptake of F68-VES/MIT micelles in MDA-MB-231 cells was assessed by using flow cytometry, and autofluorescence of MIT was observed by IN Cell Analyzer 2000. As shown in Figure 8A, the cellular accumulation of MIT occurred in a time-dependent manner in both free MIT and F68-VES/MIT micelles treatment groups. Moreover, compared to free MIT, F68-VES/MIT micelles exhibited an enhanced uptake of MIT in cells after cellular
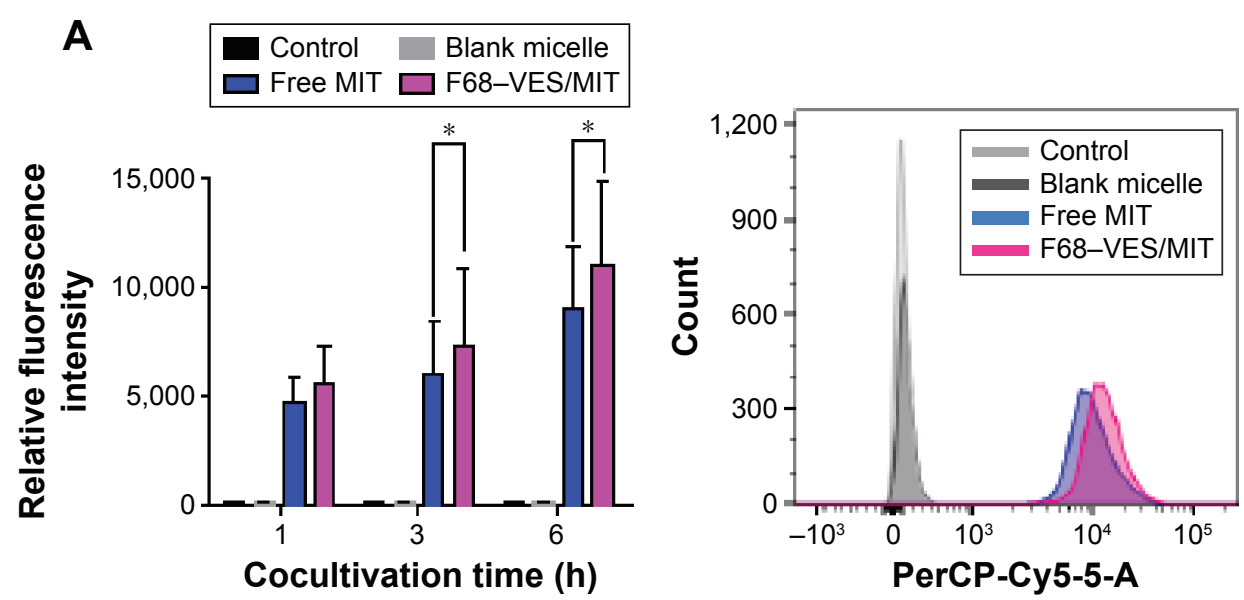

B

DAPI
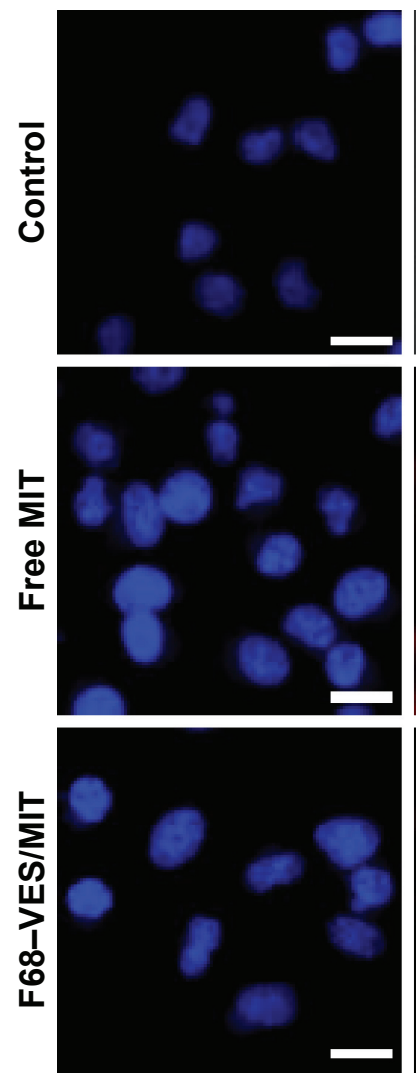

Cy5
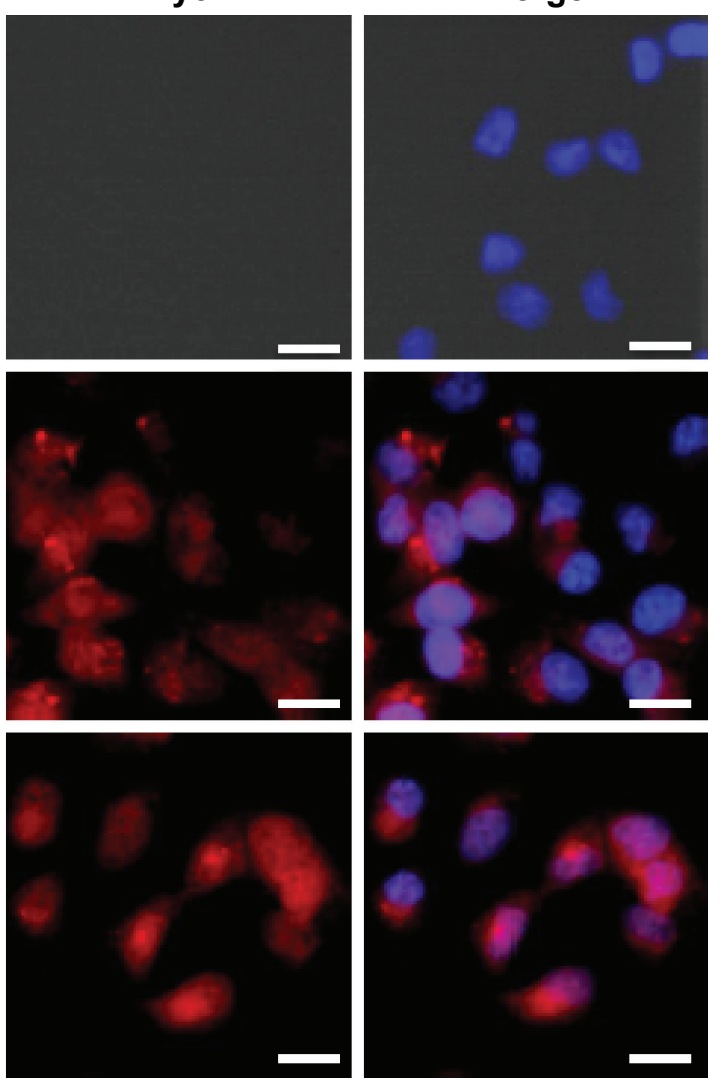

Figure 8 Cellular uptake of MIT released from F68-VES/MIT micelles.

Notes: (A) Fluorescence data of cellular uptake by MDA-MB-23I cells. (B) Fluorescent images of cellular uptake of free MIT and MIT-loaded F68-VES micelles by MDA-MB$23 \mathrm{I}$ cells. Error bar represents the standard deviation value of three experiments. The scale bars correspond to $20 \mu \mathrm{m}$ in all the images. $* P<0.05$.

Abbreviations: MIT, mitoxantrone; F68-VES/MIT micelles, mitoxantrone-loaded Pluronic F68-conjugated vitamin E succinate polymer micelles; h, hours. 
exposure for 1 hour, 3 hours, and 6 hours. The fluorescence intensity in cells incubated with $2 \mu \mathrm{M}$ F68-VES/MIT micelles was $22.4 \%$ higher than that in cells incubated with free MIT.

The intracellular uptake of F68-VES/MIT was further visualized with a fluorescent microscope. After a 6-hour treatment, cells treated with F68-VES/MIT micelles exhibited stronger red fluorescence than those treated with free MIT (Figure 8B), demonstrating better efficiency of entry into MDA-MB-231 cells in F68-VES/MIT micelles than in free MIT, which was consistent with the flow cytometry analysis results. The enhanced cellular uptake of F68-VES/MIT micelles caused increased accumulation of MIT in cells and eventually led to enhanced cytotoxicity and apoptosis.

\section{Conclusion}

The developed MIT-loaded F68-VES micelles had the characteristics of low CMC, optimal particle size with uniform appearance, high absolute zeta potential, EE and DL. The stability studies and in vitro drug release behavior indicated that F68-VES/MIT micelles had high stability and sustained in vitro drug release pattern. In cellular uptake assay, higher cellular uptake of F68-VES/ MIT micelles than free MIT in MDA-MB-231 cells demonstrated that F68-VES polymer micelles were the effective carrier to deliver MIT through the cell membrane. In pharmacological studies, compared to free MIT, MIT-loaded F68-VES micelles showed more cytotoxicity on MDA-MB-231 and MCF-7 cells. Moreover, F68-VES/ MIT micelles had a greater effect on inducing cell apoptosis in MDA-MB-231 cells than free MIT. Collectively, F68-VES micelles have the potential to become the ideal carrier for delivering chemotherapeutic agents to cancer cells, which makes great sense of performing further investigations through in vivo studies as well as clinical applications.

\section{Acknowledgments}

This study was supported by the Macao Science and Technology Development Fund (102/2012/A3), the Research Fund of the University of Macau (MYRG201400033-ICMS-QRCM, MYRG2014-00051-ICMS-QRCM, MYRG2015-00171-ICMS-QRCM), and the National Natural Science Foundation of China (81403120). This study was also supported by the Support Program of the Institute of Chinese Materia Medica, China Academy of Chinese Medical Sciences (Z02063, Z184).

\section{Disclosure}

The authors report no conflicts of interest in this work.

\section{References}

1. Pedrosa LR, ten Hagen TL, Suess R, et al. Short-chain glycoceramides promote intracellular mitoxantrone delivery from novel nanoliposomes into breast cancer cells. Pharm Res. 2015;32(4):1354-1367.

2. Barar J, Kafil V, Majd MH, et al. Multifunctional mitoxantrone-conjugated magnetic nanosystem for targeted therapy of folate receptor-overexpressing malignant cells. J Nanobiotechnology. 2015;13:26.

3. Guerriero E, Sorice A, Capone F, et al. Vitamin C effect on mitoxantroneinduced cytotoxicity in human breast cancer cell lines. PLoS One. 2014; 9(12):e115287.

4. Schmid P, Flath B, Akrivakis K, et al. Gemcitabine and mitoxantrone in metastatic breast cancer: a phase-I-study. Invest New Drugs. 2005; 23(4):349-356.

5. Ferrer A, Marce S, Bellosillo B, et al. Activation of mitochondrial apoptotic pathway in mantle cell lymphoma: high sensitivity to mitoxantrone in cases with functional DNA-damage response genes. Oncogene. 2004;23(55):8941-8949.

6. Kataoka K, Harada A, Nagasaki Y. Block copolymer micelles for drug delivery: design, characterization and biological significance. Adv Drug Deliv Rev. 2001;47(1):113-131.

7. Kim S, Shi Y, Kim JY, Park K, Cheng JX. Overcoming the barriers in micellar drug delivery: loading efficiency, in vivo stability, and micelle-cell interaction. Expert Opin Drug Deliv. 2010;7(1):49-62.

8. Bildstein L, Dubernet C, Couvreur P. Prodrug-based intracellular delivery of anticancer agents. Adv Drug Deliv Rev. 2011;63(1-2):3-23.

9. Hu XL, Jing XB. Biodegradable amphiphilic polymer-drug conjugate micelles. Expert Opin Drug Deliv. 2009;6(10):1079-1090.

10. Peer D, Karp JM, Hong S, FaroKHzad OC, Margalit R, Langer R. Nanocarriers as an emerging platform for cancer therapy. Nat Nanotechnol. 2007;2(12):751-760.

11. Tian Y, Mao SR. Amphiphilic polymeric micelles as the nanocarrier for peroral delivery of poorly soluble anticancer drugs. Expert Opin Drug Deliv. 2012;9(6):687-700.

12. Aoki N, Tamura M, Ohyashiki JH, Sugaya M, Hisatomi H. Poloxamer 188 enhances apoptosis in a human leukemia cell line. Mol Med Rep. 2010;3(4):669-672.

13. Cha M-H, Choi J, Choi BG, et al. Synthesis and characterization of novel thermo-responsive F68 block copolymers with cell-adhesive RGD peptide. J Colloid Interface Sci. 2011;360(1):78-85.

14. Song YZ, Tian QJ, Huang ZJ, et al. Self-assembled micelles of novel amphiphilic copolymer cholesterol-coupled F68 containing cabazitaxel as a drug delivery system. Int J Nanomedicine. 2014;9:2307-2317.

15. Zhang J, Li Y, Fang X, Zhou D, Wang Y, Chen M. TPGS-g-PLGA/ pluronic F68 mixed micelles for tanshinone IIA delivery in cancer therapy. Int J Pharm. 2014;476(1-2):185-198.

16. Wang $\mathrm{T}, \mathrm{Wu} \mathrm{Y}$, Zeng AJ. Synthesis and Characterization of amphiphilic pluronic (F68)-1,2-dipalmitoyl-sn-glycero-3-phosphoethanolamine copolymers and their micelles as a drug carrier. J Appl Polymer Science. 2010;1(117):604-613.

17. Kulthe SS, Inamdar NN, Choudhari YM, Shirolikar SM, Borde LC, Mourya VK. Mixed micelle formation with hydrophobic and hydrophilic pluronic block copolymers: implications for controlled and targeted drug delivery. Colloids Surf B. 2011;88(2):691-696.

18. Zhao LY, Du JC, Duan YW, et al. Curcumin loaded mixed micelles composed of pluronic P123 and F68: preparation, optimization and in vitro characterization. Colloids Surf B. 2012;97:101-108.

19. Lian H, Sun J, Yu YP, et al. Supramolecular micellar nanoaggregates based on a novel chitosan/vitamin E succinate copolymer for paclitaxel selective delivery. Int J Nanomed. 2011;6:3323-3334.

20. Tao YH, Han JF, Wang XW, Dou HY. Nano-formulation of paclitaxel by vitamin $\mathrm{E}$ succinate functionalized pluronic micelles for enhanced encapsulation, stability and cytotoxicity. Colloids and Surfaces B-Biointerfaces. 2013;102:604-610. 
21. Liang N, Sun S, Li X, et al. alpha-Tocopherol succinate-modified chitosan as a micellar delivery system for paclitaxel: preparation, characterization and in vitro/in vivo evaluations. Int J Pharm. 2012;423(2): $480-488$.

22. Huang SL, Yu XH, Yang LL, et al. The efficacy of nimodipine drug delivery using mPEG-PLA micelles and mPEG-PLA/TPGS mixed micelles. Eur J Pharm Sci. 2014;63:187-198.

23. Fang XB, Xu YQ, Zhang JM, Lu XH, Wang YT, Chen MW. Synthesis and characterization of an amphiphilic linoleic acid-g-quaternary chitosan with low toxicity. J Nanomater. 2015;2015:7.

24. Lv SX, Tang ZH, Zhang DW, et al. Well-defined polymer-drug conjugate engineered with redox and $\mathrm{pH}$-sensitive release mechanism for efficient delivery of paclitaxel. J Control Release. 2014;194:220-227.

25. Tang S, Yin Q, Su J, et al. Inhibition of metastasis and growth of breast cancer by $\mathrm{pH}$-sensitive poly (beta-amino ester) nanoparticles co-delivering two siRNA and paclitaxel. Biomaterials. 2015; 48:1-15.
26. Ke XY, Ng VWL, Gao SJ, Tong YW, Hedrick JL, Yang YY. Co-delivery of thioridazine and doxorubicin using polymeric micelles for targeting both cancer cells and cancer stem cells. Biomaterials. 2014;35(3): 1096-1108.

27. Yang C, Attia ABE, Tan JPK, et al. The role of non-covalent interactions in anticancer drug loading and kinetic stability of polymeric micelles. Biomaterials. 2012;33(10):2971-2979.

28. Honary S, Zahir F. Effect of zeta potential on the properties of nano-drug delivery systems - a review (part 1). Trop J Pharm Res. 2013;12(2): 255-264.

29. Gao Y, Li LB, Zhai G. Preparation and characterization of pluronic/ TPGS mixed micelles for solubilization of camptothecin. Colloids SurfB. 2008;64(2):194-199.
International Journal of Nanomedicine

\section{Publish your work in this journal}

The International Journal of Nanomedicine is an international, peerreviewed journal focusing on the application of nanotechnology in diagnostics, therapeutics, and drug delivery systems throughout the biomedical field. This journal is indexed on PubMed Central, MedLine, CAS, SciSearch ${ }^{\circledR}$, Current Contents ${ }^{\circledR} /$ Clinical Medicine,

\section{Dovepress}

Journal Citation Reports/Science Edition, EMBase, Scopus and the Elsevier Bibliographic databases. The manuscript management system is completely online and includes a very quick and fair peer-review system, which is all easy to use. Visit http://www.dovepress.com/ testimonials.php to read real quotes from published authors. 